\title{
Crystalline phase detection in glass ceramics by EPR spectroscopy
}

\author{
A. Antuzevics*, U. Rogulis, A. Fedotovs, A.I. Popov \\ Institute of Solid State Physics, University of Latvia, 8 Kengaraga, LV-1069 Riga, Latvia
}

* Corresponding author
E-mail: andris.antuzevics@gmail.com

\section{Abstract.}

The advances of EPR spectroscopy for the detection of activators as well as determining their local structure in the crystalline phase of glass ceramics is considered. The feasibility of d-element $\left(\mathrm{Mn}^{2+}\right.$, $\left.\mathrm{Cu}^{2+}\right)$ and f-element $\left(\mathrm{Gd}^{3+}, \mathrm{Eu}^{2+}\right)$ ion probes for the investigation of glass ceramics is discussed.

In the case of $\mathrm{Mn}^{2+}$, the information is obtained from the EPR spectrum superhyperfine structure, for $\mathrm{Gd}^{3+}$ and $\mathrm{Eu}^{2+}$ probes - from the $\mathrm{EPR}$ spectrum fine structure, whereas for $\mathrm{Cu}^{2+}$ ions the changes in the EPR spectrum shape could be useful. The examples of EPR spectra of the above-mentioned probes in oxyfluoride glass ceramics are illustrated.

Keywords: electron paramagnetic resonance; paramagnetic ions; glass ceramics.

\section{Introduction}

An actual problem for the development of glass ceramics is ensuring that the majority of dopant ions embed the crystalline phase of the material. Crystalline phases in glass ceramics are usually detected by X-ray diffraction (XRD) measurements and visualized by transmission electron microscopy (TEM) photographs, however, these methods do not provide the essential information about the activator local structure. Absorption and luminescence spectra, on the other hand, can indicate changes in the local environment around the luminescence centres, however, structure sensitive magnetic resonance spectroscopy techniques should be employed to reveal the detailed nature of defects in glass ceramics. Electron paramagnetic resonance (EPR) is one of the most convenient and informative methods for the study of point defects in crystals and glasses [1-11], however, there has been only a limited number of applications to glass ceramics [12-21]. 
A choice of optimal temperature is necessary to ensure the best EPR signal intensity and avoid temperature caused line broadening in the spectra. For this reason EPR measurements are usually done at cryogenic temperatures, e.g. at liquid nitrogen boiling point (77 K).

The present paper provides a review of EPR results of paramagnetic probes studied in glass ceramics as well as our recent data on $\mathrm{Mn}^{2+}, \mathrm{Cu}^{2+}$ and $\mathrm{Gd}^{3+}$ ions in oxyfluoride glass ceramics.

\section{Experimental}

Glasses were prepared by the conventional melt quenching technique. Batches of $8 \mathrm{~g}$ (see Table 1) were mixed and melted at $1450 \pm 10{ }^{\circ} \mathrm{C}$ in covered alumina crucibles and quenched by pouring the melts onto a stainless steel plate. The glass ceramics were obtained by an isothermal heat treatment of the transparent precursor glass (PG) at the indicated temperature. The sample abbreviation includes the paramagnetic probe $(\mathrm{Mn}, \mathrm{Cu}$ or $\mathrm{Gd})$ as well as the crystalline phase of the glass ceramic samples $(\mathrm{C}-$ $\left.\mathrm{CaF}_{2}, \mathrm{~S}-\mathrm{SrF}_{2}, \mathrm{~B}-\mathrm{BaF}_{2}, \mathrm{~N}-\mathrm{NaLaF}_{4}\right)$. The last number in the sample abbreviation is the heating temperature in ${ }^{\circ} \mathrm{C}$. For example, Mn_C_700 is the glass ceramic obtained after heating the Mn_C_PG (precursor glass) composition sample at $700{ }^{\circ} \mathrm{C}$ for $1 \mathrm{~h}$.

X-ray diffraction (XRD) measurements with PANalytical X'Pert Pro diffractometer were made to identify the crystalline phases present in glass ceramics

Table 1. Compositions used for glass preparation.

\begin{tabular}{ll}
\hline Abbreviation & Composition \\
\hline $\mathrm{Mn} \_\mathrm{C}$ & $46 \mathrm{SiO}_{2}-20 \mathrm{Al}_{2} \mathrm{O}_{3}-8 \mathrm{CaCO}_{3}-25 \mathrm{CaF}_{2}-0.1 \mathrm{MnO}$ \\
$\mathrm{Cu} \_\mathrm{C}$ & $46 \mathrm{SiO}_{2}-20 \mathrm{Al}_{2} \mathrm{O}_{3}-8 \mathrm{CaCO}_{3}-25 \mathrm{CaF}_{2}-0.1 \mathrm{CuO}$ \\
$\mathrm{Gd} \_\mathrm{N}$ & $63 \mathrm{SiO}_{2}-7 \mathrm{Al}_{2} \mathrm{O}_{3}-16 \mathrm{Na}_{2} \mathrm{CO}_{3}-9 \mathrm{NaF}_{-}-5 \mathrm{LaF}_{3}-0.1 \mathrm{GdF}_{3}$ \\
$\mathrm{Gd} \_\mathrm{S} \_01$ & $40 \mathrm{SiO}_{2}-25 \mathrm{Al}_{2} \mathrm{O}_{3}-15 \mathrm{Na}_{2} \mathrm{CO}_{3}-1 \mathrm{EuF}_{3}-19 \mathrm{SrF}_{2}-0.1 \mathrm{GdF}_{3}$ \\
Gd_S_10 & $40 \mathrm{SiO}_{2}-25 \mathrm{Al}_{2} \mathrm{O}_{3}-15 \mathrm{Na}_{2} \mathrm{CO}_{3}-1 \mathrm{EuF}_{3}-18 \mathrm{SrF}_{2}-1.0 \mathrm{GdF}_{3}$ \\
Gd_S_40 & $40 \mathrm{SiO}_{2}-25 \mathrm{Al}_{2} \mathrm{O}_{3}-15 \mathrm{Na}_{2} \mathrm{CO}_{3}-1 \mathrm{EuF}_{3}-15 \mathrm{SrF}_{2}-4.0 \mathrm{GdF}_{3}$ \\
\hline
\end{tabular}

EPR spectra were measured at $77 \mathrm{~K}$ with a conventional $\mathrm{X}$-band spectrometer $(\approx 9.1 \mathrm{GHz})$. The magnetic field was callibrated using a polycrystalline DPPH reference - an organic chemical compound which is commonly used in EPR spectroscopy. 
The structural models were visualised using VESTA software. [22,23]

\section{Results and discussion}

\section{1. $\mathrm{Mn}^{2+}$}

Manganese is one of the most commonly used paramagnetic probes for local structure investigations via EPR spectroscopy. The characteristic $\mathrm{Mn}^{2+} \mathrm{EPR}$ spectrum arises from the hyperfine structure (HFS) interaction between the $\mathrm{d}^{5}$ shell electron cloud effective spin $S=5 / 2$ and $100 \%$ abundant ${ }^{55} \mathrm{Mn}$ isotope nuclear spin $I=5 / 2$. The resonance positions in single crystals are also strongly dependent on the $\mathrm{Mn}^{2+}$ centre symmetry determined by the surrounding ligand field. Thus, the effective spin-Hamiltonian (SH) is:

$H=\beta g B S+\sum_{k} \sum_{q} f_{k} b_{k}^{q} O_{k}^{q}+A S I$

where $\beta$ is the Bohr magneton; $g$ - the $g$-factor; $B$ - the applied magnetic field; $f_{k}$ - numerical constants; $b_{k}^{q}$ - zero field splitting (ZFS) parameters depending on the site symmetry; $O_{k}^{q}-$ spin operators and $A$ - the hyperfine interaction constant.

In vitreous media $\mathrm{Mn}^{2+} \mathrm{EPR}$ spectrum consists of a signature sextet (see figure 1) centred at $g=2.0$ caused by the hyperfine interaction, whereas the angularly dependent ZFS part usually is not resolved. The magnetic field range of the spectrum is characterized by the magnitude of isotropic hyperfine interaction constant $A$, and is an indicator of local chemical environment around the impurity. A more ionic bonding to the surrounding ligands results in a larger $A$ value. [24]

In $\mathrm{InF}_{3}$ based glass ceramics, heat treatment of the precursor glass has caused the increase of the signal/noise ratio of the characteristic sextet indicating localization of a larger part of $\mathrm{Mn}^{2+}$ ions in highly order sites. [12] In tellurite borate glass ceramics, local $\mathrm{Mn}^{2+}$ site symmetry has been monitored from SH parameters as a function of manganese content in the composition. [13] Oxyfluoride glass ceramics containing fluorite structure crystallites $\left(\mathrm{CaF}_{2}, \mathrm{SrF}_{2}, \mathrm{BaF}_{2}\right)$ have shown particularly interesting results additional superhyperfine structure (SHFS) splitting of each spectral line after the precipitation of fluoride nanocrystals in the glass matrix can be observed. [14-17] 
Figure 1 shows Mn_C composition glass and the respective glass ceramic obtained after the heat treatment at $700 \pm 10{ }^{\circ} \mathrm{C}$. The superimposed SHFS in the glass ceramic is caused by the interaction between the $\mathrm{Mn}^{2+}$ effective spin $S$ and the spins of $N$ nearest fluorine nuclei $I_{F}=1 / 2$. As a result, each HFS line is split into $2 N I_{F}+1$ components with binomial intensity distribution. Splitting into 9 components in our case means that $\mathrm{Mn}^{2+}$ ions substitute $\mathrm{Ca}^{2+}$ ions in $\mathrm{CaF}_{2}$ nanocrystals and are surrounded by 8 equidistant fluorine nuclei. The results obtained here are consistent with Refs. [14-17].

EPR studies of manganese paramagnetic probes in glass ceramics thus yields information not only about the formation of crystallites in the glass matrix, but also helps to assess the first coordination sphere around the dopant ions in the crystalline phase.

\section{2. $\mathrm{Cu}^{2+}$}

Copper ions are commonly used spin probes for local structure investigations in vitreous media. [2529] For the interpretation of characteristic $\mathrm{Cu}^{2+}$ spectrum (see fig. 2), an axial SH should be applied:

$$
H=\beta g_{\|} B_{z} S_{z}+\beta g_{\perp}\left(B_{x} S_{x}+B_{y} S_{y}\right)+A_{\|} S_{z} I_{z}+A_{\perp}\left(S_{x} I_{x}+S_{y} I_{y}\right)
$$

The $\mathrm{Cu}^{2+}$ ion has $S=1 / 2$ and $I=3 / 2$ for both isotopes ${ }^{63} \mathrm{Cu}$ and ${ }^{65} \mathrm{Cu}$ and thus a HFS splitting into four resonances is expected for both parralel and perpendicular components of the $g$ tensor. Such spectral features are characteristic of $\mathrm{Cu}^{2+}$ ions in distorted octahedral sites elongated along the $\mathrm{z}$-axis. The $\mathrm{SH}$ parameter values indicate the strength of the surrounding ligand field.

Literature about the incorporation of copper ions in the crystalline phase of glass ceramics, on the other hand, is somewhat scarce. Previous study of $\mathrm{Cu}^{2+}$-doped $\mathrm{InF}_{3}$ based glass ceramics has observed a relatively broad Gaussian line superimposing the glassy spectrum after the heat treatment of the precursor glass, however, its origin was related to oxygen/water content in the atmosphere during the glass preparation. [12] Here figure 2 shows the EPR spectra of $\mathrm{Cu}_{-} \mathrm{C}$ composition glass and the corresponding glass ceramic heated at $700 \pm 10{ }^{\circ} \mathrm{C}$. Spectrum shape near $g=2.0$ has changed, however, the lack of structure in this resonance prohibits additional information about the nature of this paramagnetic centre. Nevertheless, changes in the EPR spectra shape observed after the creation of crystallites in the glass allows, in principle, to detect the crystalline phase in glass ceramics. 


\section{3. $\mathrm{Gd}^{3+}$}

Most potential applications of glass ceramics revolve around the luminescence of rare earth ions, therefore, the local structure of trivalent defects in these systems is of great interest. Unfortunately, direct observation of most rare earths is problematic either due to the lack of paramagnetic ground state or by the necessity of liquid helium temperatures to observe the spectrum. The unusually long spin-lattice relaxation time of gadolinium makes it one of the most useful paramagnetic probes for studying the "glass $\rightarrow$ glass ceramic" transition even at room temperature. The ground state of $\mathrm{Gd}^{3+}$ is an S-state $\left(4 \mathrm{f}^{7}\right.$; $S=7 / 2$ ) and the splitting in external magnetic field is described by:

$H=\beta g B S+\sum_{k} \sum_{q} f_{k} b_{k}^{q} O_{k}^{q}$

$\mathrm{Gd}^{3+}$ in disordered media is characterized by the signature U-type (ubiquitous) spectrum with resonances at $g_{\text {eff }}=6.0,2.8$ and 2.0. Coordination with a relatively large number of ligands at inequivalent distances can be simulated by taking a relatively broad distribution in second-order ZFS parameters. [30,31] In crystalline media, the nature of $\mathrm{Gd}^{3+}$ local environment is host sensitive and can yield valuable information about the material in study. [32]

After precipitation of a crystalline phase in the glass matrix, intensive resonances centred at $g=2.0$ usually superimpose the U-type spectrum. $[12,18]$ An example is shown in figures 3 and $4-$ Gd_N composition glass and the corresponding glass ceramic containing $\mathrm{NaLaF}_{4}$ nanocrystals. The XRD spectra clearly show the formation of $\mathrm{NaLaF}_{4}$ nanocrystals in the glass matrix. Meanwhile, the intense new EPR signal indicates efficient incorporation of trivalent rare earth impurities in the crystalline phase of glass ceramics. For a better understanding of gadolinium centres in $\mathrm{NaLaF}_{4}, \mathrm{EPR}$ angular variations in single crystalline sample should be studied.

In order to extract the most from EPR spectra, an optimal concentration of paramagnetic impurities should be used. In figure 5 glass ceramics containing $\mathrm{SrF}_{2}$ crystalline phase and $\mathrm{Gd}^{3+}$ ions in different concentrations are compared. The fine structure is best resolved at relatively lower dopant concentration and is significantly broadened due to the dipolar interaction between the paramagnetic centres at higher 
doping levels. At high concentration, various forms of composite defects such as gadolinium ion pairs and clusters may also be present.

$\mathrm{Gd}^{3+}$ in oxyfluoride glass ceramics containing fluorite structure crystalline phase have been studied recently. $[19,20]$ Main results for compositions containing $\mathrm{CaF}_{2}, \mathrm{SrF}_{2}$ and $\mathrm{BaF}_{2}$ are summarized in figure 6. EPR spectrum structure strongly depends on the local symmetry around $\mathrm{Gd}^{3+}$ impurities in these nanocrystals. When trivalent gadolinium replaces the divalent cation, a charge compensation is necessary. Depending on the compensator orientation in the lattice, various forms of $\mathrm{Gd}^{3+}$ centres are possible in fluorite structure crystals - cubic centres when the compensator is located far from the impurity [33], tetragonal centres where usually an interstitial fluorine anion located along [100] direction distorts the original cubic configuration [34] and trigonal centres if the charge is compensated by an additional impurity along the [111] direction [35]. The mentioned $\mathrm{Gd}^{3+}$ symmetries in fluorite type crystals are illustrated in figure 7 . When $\mathrm{Gd}^{3+}$ replaces the similarly sized $\mathrm{Ca}^{2+}$ ions in glass ceramics containing $\mathrm{CaF}_{2}$, the EPR spectrum is dominated by $\mathrm{Gd}^{3+}$ in local cubic symmetry crystal field [19], whereas substitution of significantly larger $\mathrm{Ba}^{2+}$ ions in glass ceramics containing $\mathrm{BaF}_{2}$ leads to an $\mathrm{EPR}$ signal characterized by SH parameters for trigonal site symmetry [20].

To summarize, EPR spectral features of $\mathrm{Gd}^{3+}$ ions are sensitive to the local environment and are effective for detecting the presence of crystalline phase in glass ceramics. The results obtained from the studies of $\mathrm{Gd}^{3+}$ EPR spectra could also be used to analyse non-magnetic trivalent rare earth ions, local structure of which cannot be studied by magnetic resonance spectroscopy.

\section{4. $\mathrm{Eu}^{2+}$}

The electron configuration of $\mathrm{Eu}^{2+}$ ground state is the same as for $\mathrm{Gd}^{3+}\left(4 \mathrm{f}^{7} ; S=7 / 2\right)$, however, the EPR spectrum is complicated by the HFS interaction with europium isotopes ${ }^{151} \mathrm{Eu}$ and ${ }^{153} \mathrm{Eu}(I=5 / 2)$. As a result, each ZFS component is further split into two sets of sextets and SH (1) must be used for interpretation. In glass ceramics doped with $\mathrm{Eu}^{2+}$, the randomly orientated crystallites are, therefore, expected to generate much broader lines than similar systems with $\mathrm{Gd}^{3+}$. EPR studies of europium doped systems may also be hindered by the presence of stable non-magnetic $\mathrm{Eu}^{3+}$ ions which are generally more abundant unless special reduction has been carried out during the sample preparation. 
$\mathrm{Eu}^{2+} \mathrm{EPR}$ signal has been observed in glass ceramics containing $\mathrm{BaBr}_{2}$. Successful simulation of the spectrum with the single crystal SH data confirmed that the signal originates from the $\mathrm{BaBr}_{2}$ crystalline phase of glass ceramics. [21]

Europium doped glass ceramics are promising materials for optical applications and the luminescence properties have been studied extensively in various systems containing fluorite type nanocrystals. [3638] As well-known from the literature, the broad emission of $\mathrm{Eu}^{2+} 5 \mathrm{~d} \rightarrow 4 \mathrm{f}$ luminescence is sensitive to the local ligand field and, thus, some EPR data could contribute to a better understanding of these systems.

A recent study [39], in particular, focuses on monitoring the valence state of europium ions in different composition glass ceramics containing $\mathrm{SrF}_{2}$. Sharp lines in the EPR spectra can be observed after the heat treatment of the precursor glass at high temperatures, where $\mathrm{Eu}^{3+} \rightarrow \mathrm{Eu}^{2+}$ reduction and incorporation into crystalline phases is efficient, whereas $\mathrm{Eu}^{2+}$ ions in the glassy matrix can be detected by the signature U-type spectrum. Combining the EPR data with photoluminescence spectra allows a direct attribution of $\mathrm{Eu}^{2+}$ local structure to particular optical properties.

\section{Conclusions}

1. d-element $\left(\mathrm{Mn}^{2+}, \mathrm{Cu}^{2+}\right)$ and f-element $\left(\mathrm{Gd}^{3+}, \mathrm{Eu}^{2+}\right)$ paramagnetic probes are suitable for detecting the incorporation of activators in the crystalline phase of glass ceramics.

2. Variation of $\mathrm{Mn}^{2+}$ and $\mathrm{Cu}^{2+}$ spectral shapes after the precipitation of crystalline phases in the glass matrix indicates the change of local environment around the impurities. Coordination of $\mathrm{Mn}^{2+}$ in nanocrystals can be determined if the SHFS is resolved in the EPR spectrum.

3. Intensive EPR signal emerges and overlays the glassy U-type spectrum after the heat treatment of the precursor glass if $\mathrm{Gd}^{3+}$ ions embed in the crystalline phase. The resonance positions depend strongly on the local crystalline field, therefore, local site symmetry around the impurity can be determined.

4. Europium ion valence state can be monitored from EPR spectra measurements. Similarly to $\mathrm{Gd}^{3+}, \mathrm{Eu}^{2+}$ ions in the glass matrix exhibit the signature U-type spectrum and incorporation into 
crystalline phases of glass-ceramics can be determined via additional EPR spectrum fine structure.

\section{Acknowledgements.}

The authors thank Meldra Kemere and Dr. Edgars Elsts for sample synthesis and Reinis Ignatans for XRD measurements. Financial support of Latvian-Ukrainian Joint Research Project No. LV-UA/2016/1 is acknowledged. Institute of Solid State Physics, University of Latvia as the Center of Excellence has received funding from the European Union's Horizon 2020 Framework Programme H2020WIDESPREAD-01-2016-2017-TeamingPhase2 under grant agreement No. 739508, project CAMART²

\section{References}

[1] J. Kliava, J. Purans, Journal of Magnetic Resonance 40, 33 (1980). DOI: 10.1016/00222364(80)90227-9

[2] U. Rogulis, C. Dietze, T. Pawlik, T. Hangleiter, J.M. Spaeth, Journal of applied physics 80, 2430 (1980). DOI: $10.1063 / 1.363078$

[3] A. Antuzevics, U. Rogulis, A. Fedotovs, D. Berzins, V.N. Voronov, J. Purans, Phys. Scr. 90 (2015). DOI: https://doi.org/10.1088/0031-8949/90/11/115801

[4] T. Kärner, S. Dolgov, A. Lushchik, N. Mironova-Ulmane, S. Nakonechnyi, E. Vasil'chenko, Radiat. Eff. Defects Solids 155, 171 (2001). DOI: 10.1080/10420150108214110

[5] Y.V. Kolk and A.C. Lushchik, Sov. Phys. Solid State 28, 805 (1986) [Fiz. Tverd. Tela 28, 1432 (1986)]

[6] A.Ch. Lushchik and A.G. Frorip, Phys. Status Solidi B 161, 525 (1990). DOI: $10.1002 /$ pssb.2221610208

[7] S. Dolgov, T. Kärner, A. Lushchik, A. Maaroos, N. Mironova-Ulmane, S. Nakonechnyi, Radiat. Prot. Dosim. 100, 127 (2002). DOI: 10.1093/oxfordjournals.rpd.a005828

[8] N. Mironova-Ulmane, V. Skvortsova, A. Pavlenko, E. Feldbach, A. Lushchik, Ch. Lushchik, V. Churmanov, D. Ivanov, V. Ivanov, E. Aleksanyan, Radiat. Meas. 90, 122 (2016). DOI: 10.1016/j.radmeas.2015.12.020

[9] I. Romet, M. Buryi, G. Corradi, E. Feldbach, V. Laguta, E. Tichy-Rács, V. Nagirnyi, Optical Materials 70, 184 (2017). DOI: https://doi.org/10.1016/j.optmat.2017.05.032

[10] V. Seeman, S. Dolgov, and A. Maaroos, Physica B: Condensed Matter 513, 69 (2017). DOI: https://doi.org/10.1016/j.physb.2017.03.010

[11] S.A. Dolgov, T. Kärner, A. Lushchik, A. Maaroos, S. Nakonechnyi, E. Shablonin, Phys. Solid State 53, 1244 (2011) [Fiz. Tverd. Tela 53, 1179 (2011)] DOI: 10.1134/S1063783411060084 
[12] R.W.A. Franco, J.F. Lima, C.J. Magon, J.P. Donoso, Y. Messaddeq, J. Non. Cryst. Solids 352, 3414 (2006). DOI: 10.1016/j.jnoncrysol.2006.02.107

[13] T. Satyanarayana, M.A. Valente, G. Nagarjuna, N. Veeraiah, J. Phys. Chem. Solids 74, 229 (2013). DOI: 10.1016/j.jpcs.2012.09.011

[14] A. Fedotovs, D. Berzins, O. Kiselova, A. Sarakovskis, IOP Conf. Ser. Mater. Sci. Eng. 38, 12047 (2012). DOI: 10.1088/1757-899X/38/1/012047

[15] A. Fedotovs, D. Berzins, O. Kiselova, A. Sarakovskis, U. Rogulis, IOP Conf. Ser. Mater. Sci. Eng. 23, 12018 (2011). DOI: 10.1088/1757-899X/23/1/012018

[16] D. Berzins, A. Fedotovs, O. Kiselova, A. Sarakovskis, IOP Conf. Ser. Mater. Sci. Eng. 38, 12046 (2012). DOI: 10.1088/1757-899X/38/1/012046

[17] A. Fedotovs, D. Berzins, A. Sarakovskis, U. Rogulis, G. Doke, IOP Conf. Ser. Mater. Sci. Eng. 15, 12068 (2010). DOI: 10.1088/1757-899X/15/1/012068

[18] M. Mohapatra, B. Rajeswari, N.S. Hon, R.M. Kadam, M.S. Keskar, V. Natarajan, Ceram. Int. 41, 8761 (2015). DOI: 10.1016/j.ceramint.2015.03.099

[19] A. Fedotovs, A. Antuzevics, U. Rogulis, M. Kemere, R. Ignatans, J. Non. Cryst. Solids 429, 118 (2015) DOI: 10.1016/j.jnoncrysol.2015.08.036

[20] A. Antuzevics, M. Kemere, R. Ignatans, J. Non. Cryst. Solids 449, 29 (2016). DOI: 10.1016/j.jnoncrysol.2016.07.015

[21] S. Schweizer, G. Corradi, A. Edgar, J.-M. Spaeth, J. Phys. Condens. Matter 13, 2331 (2001). DOI:10.1088/0953-8984/13/10/323

[22] K. Momma, F. Izumi, J. Appl. Crystallogr. 41, 653 (2008). DOI: 10.1107/S0021889808012016

[23] K. Momma, F. Izumi, J. Appl. Crystallogr. 44, 1272 (2011). DOI: 10.1107/S0021889811038970

[24] F.J. Owens, J. Chem. Phys. 57, 118 (1972).

[25] G.N. Devde, G. Upender, V. Chandra Mouli, L.S. Ravangave, J. Non. Cryst. Solids (2015). DOI: 10.1016/j.jnoncrysol.2015.10.022

[26] S. Prakash Singh, R.P.S. Chakradhar, J.L. Rao, B. Karmakar, J. Magn. Magn. Mater. 346, 21 (2013). DOI: 10.1016/j.jmmm.2013.07.007

[27] A. Hameed, G. Ramadevudu, M. Shareefuddin, M.N. Chary, AIP Conf. Proc. 1591, 842 (2014). DOI: $10.1063 / 1.4872775$

[28] A. Bhogi, P. Kistaiah, Phys. Chem. Glas. Eur. J. Glas. Sci. Technol. Part B 56, 197 (2015). DOI: $10.13036 / 17533562.56 .5 .197$

[29] B. Sreedhar, C. Sumalatha, K. Kojima, J. Non. Cryst. Solids 192-193, 203 (1995). DOI: 10.1016/0022-3093(95)00438-6

[30] C.M. Brodbeck, L.E. Iton, J. Chem. Phys. 83, 4285 (1985). DOI: 10.1063/1.449041 
[31] C. Legein, J.Y. Buzaré, G. Silly, C. Jacoboni, J. Phys. Condens. Matter. 8, 4339 DOI: $10.1088 / 0953-8984 / 8 / 23 / 023$

[32] H.A. Buckmaster, Y.H. Shing, Phys. Status Solidi 12, 325 (1972). DOI: 10.1002/pssa.2210120202 [33] J. Sierro, Phys. Lett. 4, 178 (1963). DOI: 10.1093/jicru/ndp028

[34] W.-Q. Yang, Y. Zhang, Y. Lin, W.-C. Zheng, J. Magn. Reson. 227, 62 (2013). DOI: 10.1016/j.jmr.2012.12.003

[35] C. Yang, S. Lee, A.J. Bevolo, Phys. Rev. B 13, 2762 (1976).

[36] Q. Luo, X. Qiao, X. Fan, S. Liu, H. Yang, X. Zhang, J. Non. Cryst. Solids 354, 4691 (2008). DOI: 10.1016/j.jnoncrysol.2008.07.019

[37] Q. Luo, X. Qiao, X. Fan, X. Zhang, J. Am. Ceram. Soc. 93, 2684 (2010). DOI: 10.1111/j.15512916.2010.03756.x

[38] K. Biswas, A.D. Sontakke, R. Sen, K. Annapurna, J. Fluoresc. 22, 745 (2012). DOI: 10.1007/s10895-011-1010-4

[39] A. Antuzevics, M. Kemere, G. Krieke, R. Ignatans, Opt. Mater. 72, 749 (2017). DOI: 10.1016/j.optmat.2017.07.024 


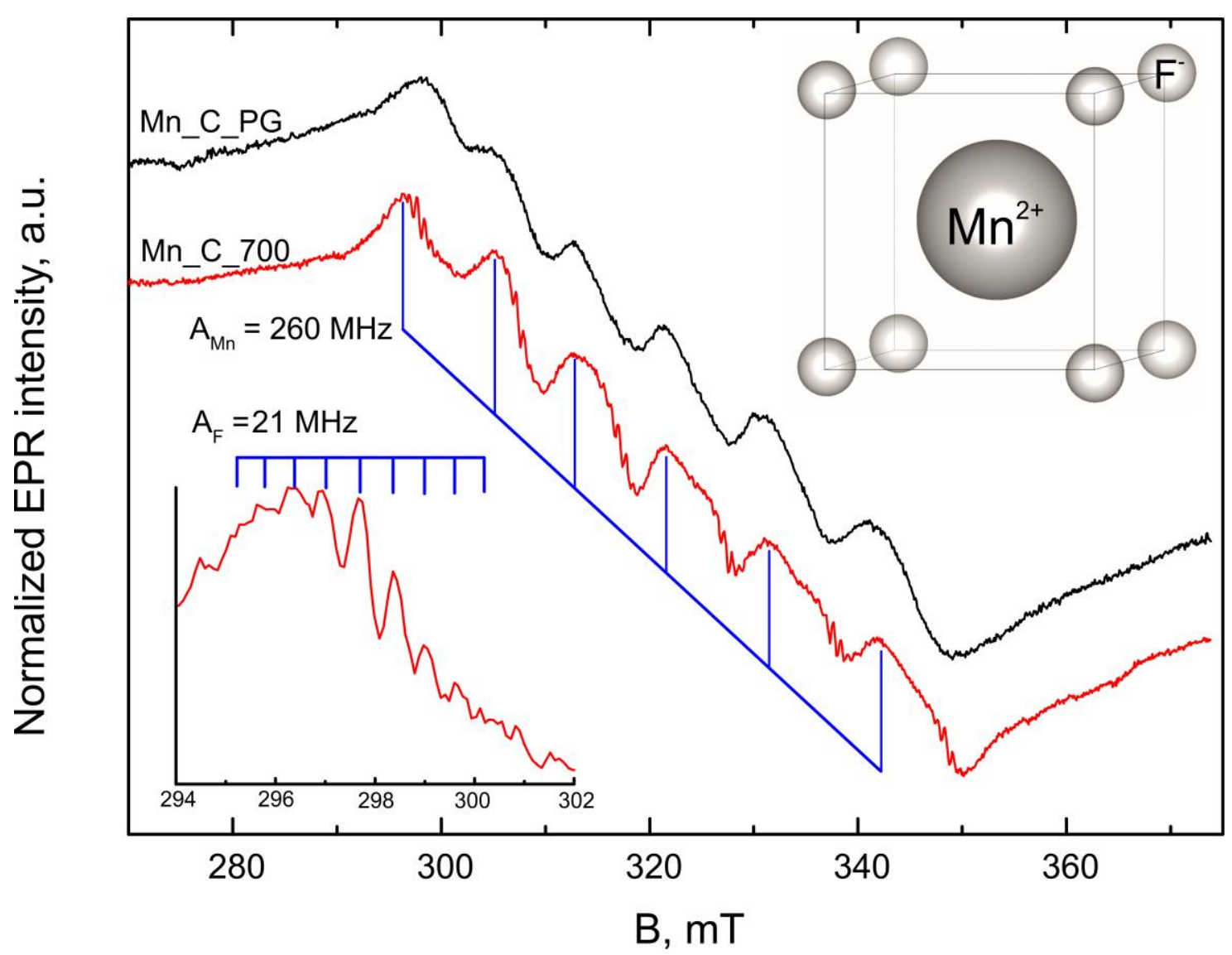

Fig. 1. EPR spectra of the manganese doped glass (black) and the glass ceramic (red) containing $\mathrm{CaF}_{2}$. Inset shows the eightfold coordinated $\mathrm{Mn}^{2+}$ site in $\mathrm{CaF}_{2}$ nanocrystals.

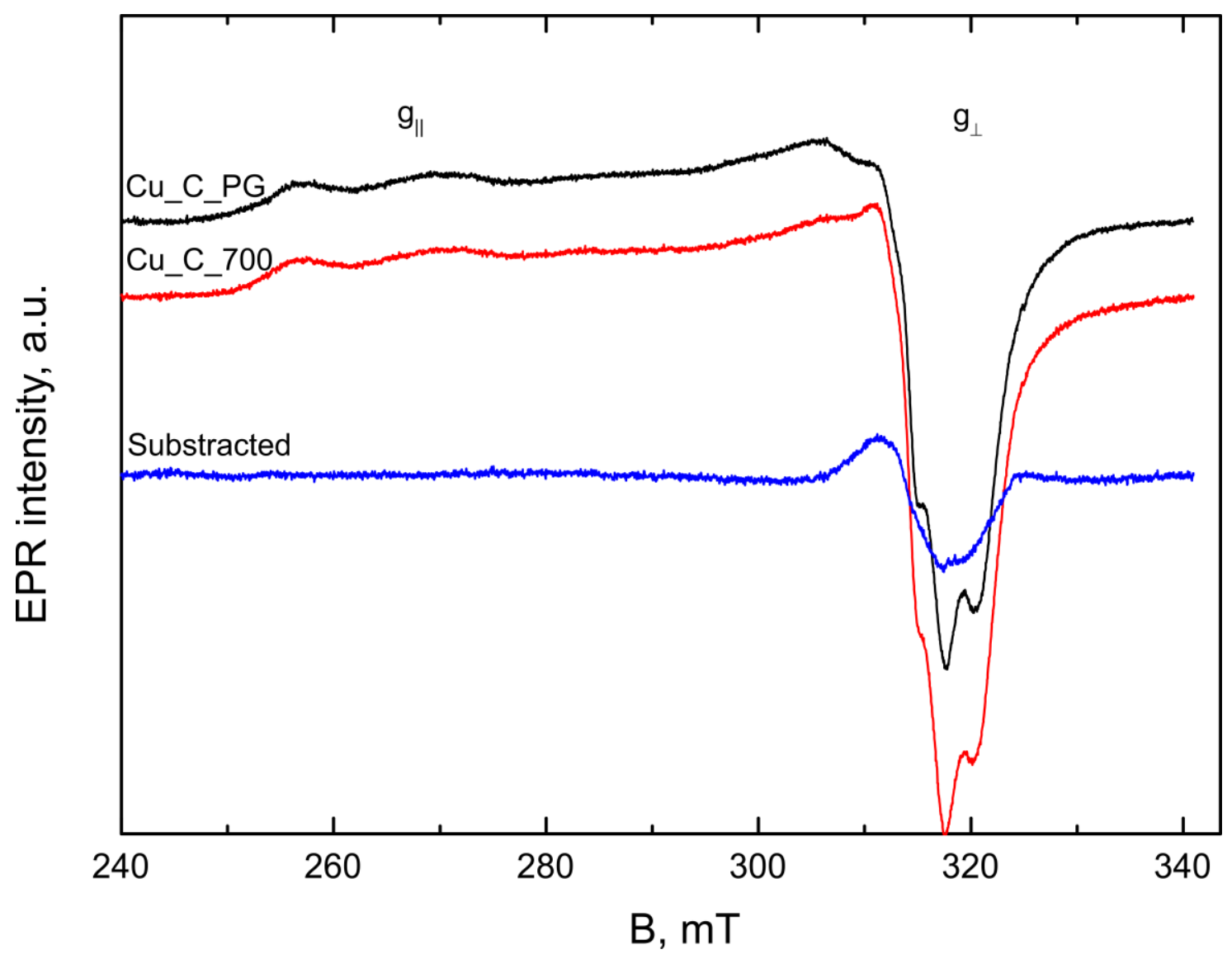


Fig. 2. EPR spectra of the copper doped glass and glass ceramic containing $\mathrm{CaF}_{2}$.

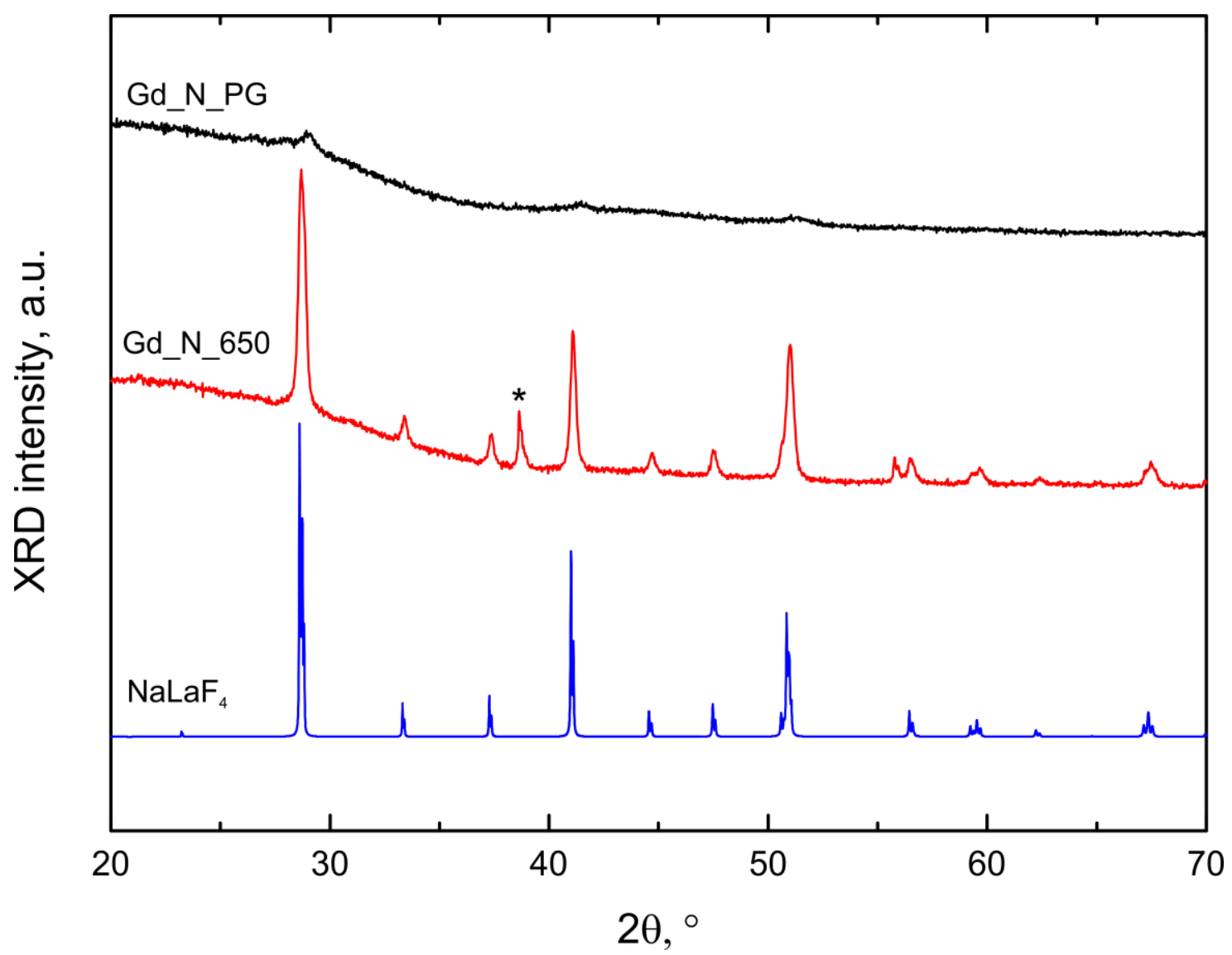

Fig. 3. XRD spectra of the gadolinium doped glass and glass ceramic containing $\mathrm{NaLaF}_{4}$. The blue curve is the calculated polycrystalline $\mathrm{NaLaF}_{4}$ diffractogram. Peak marked with * belongs to the $\mathrm{NaF}$ crystalline phase. 


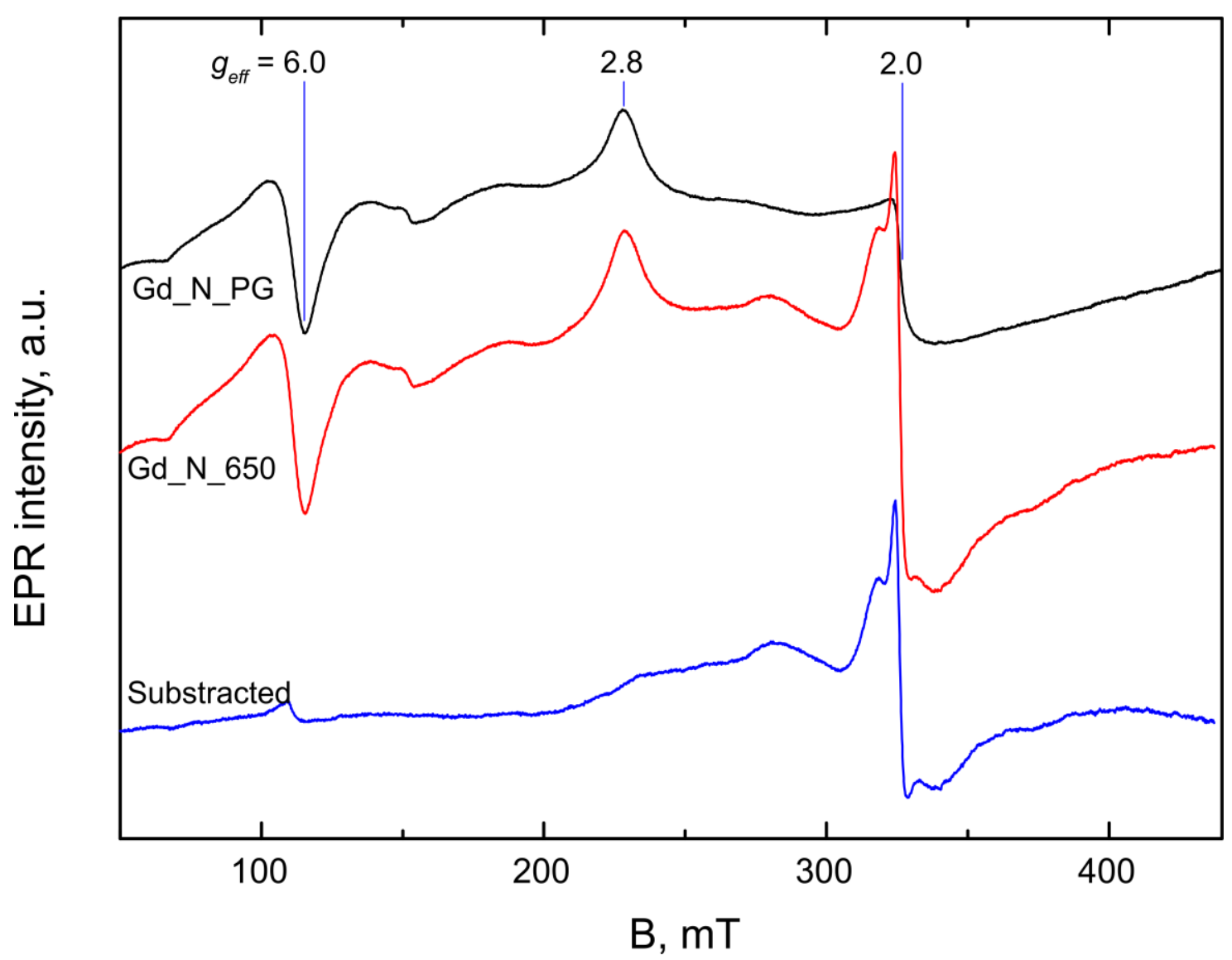

Fig. 4. EPR spectra of the gadolinium doped glass and glass ceramic containing $\mathrm{NaLaF}_{4}$.

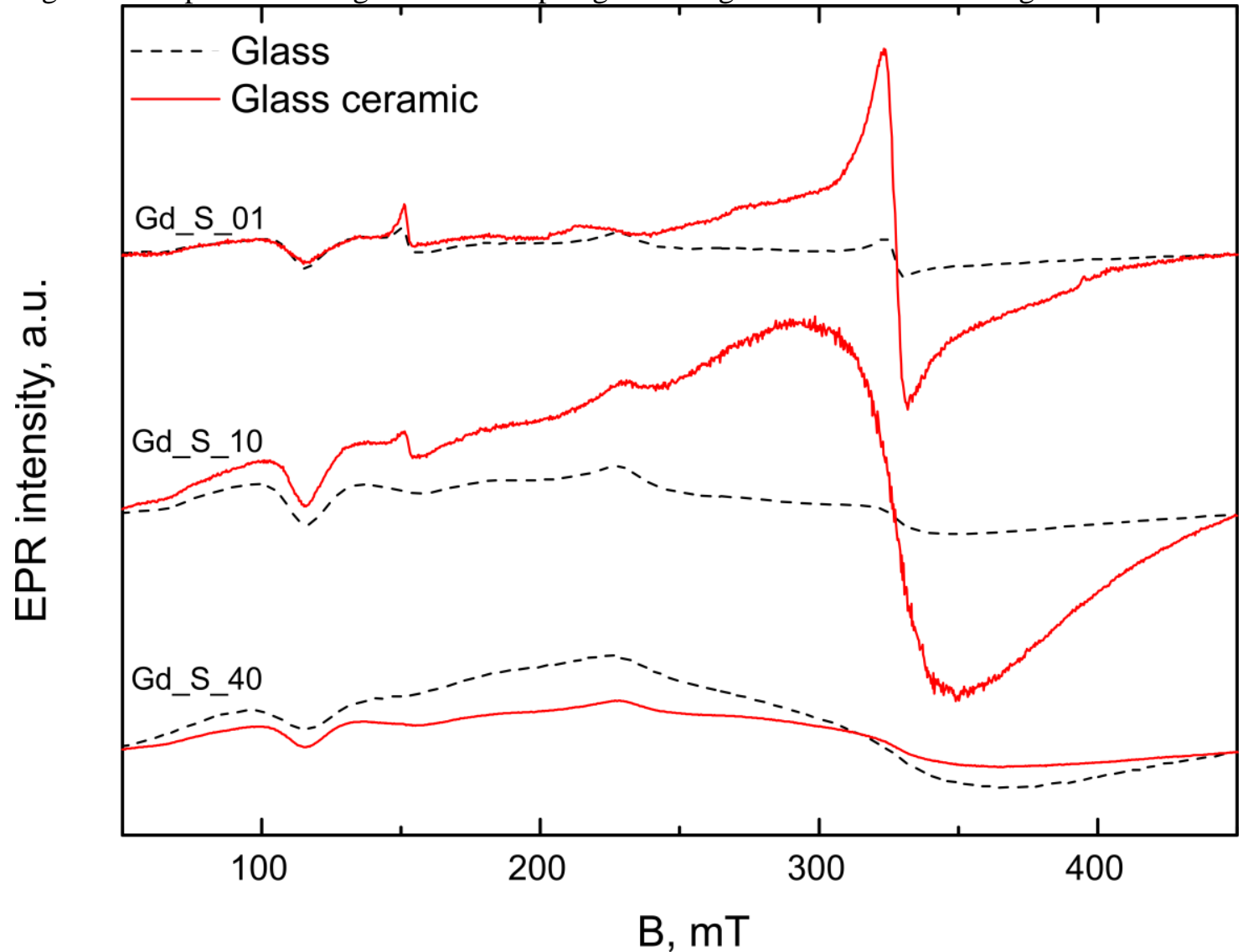

Fig. 5. $\mathrm{Gd}^{3+}$ concentration dependance of the EPR spectra of glasses and glass ceramics containing $\mathrm{SrF}_{2}$. 


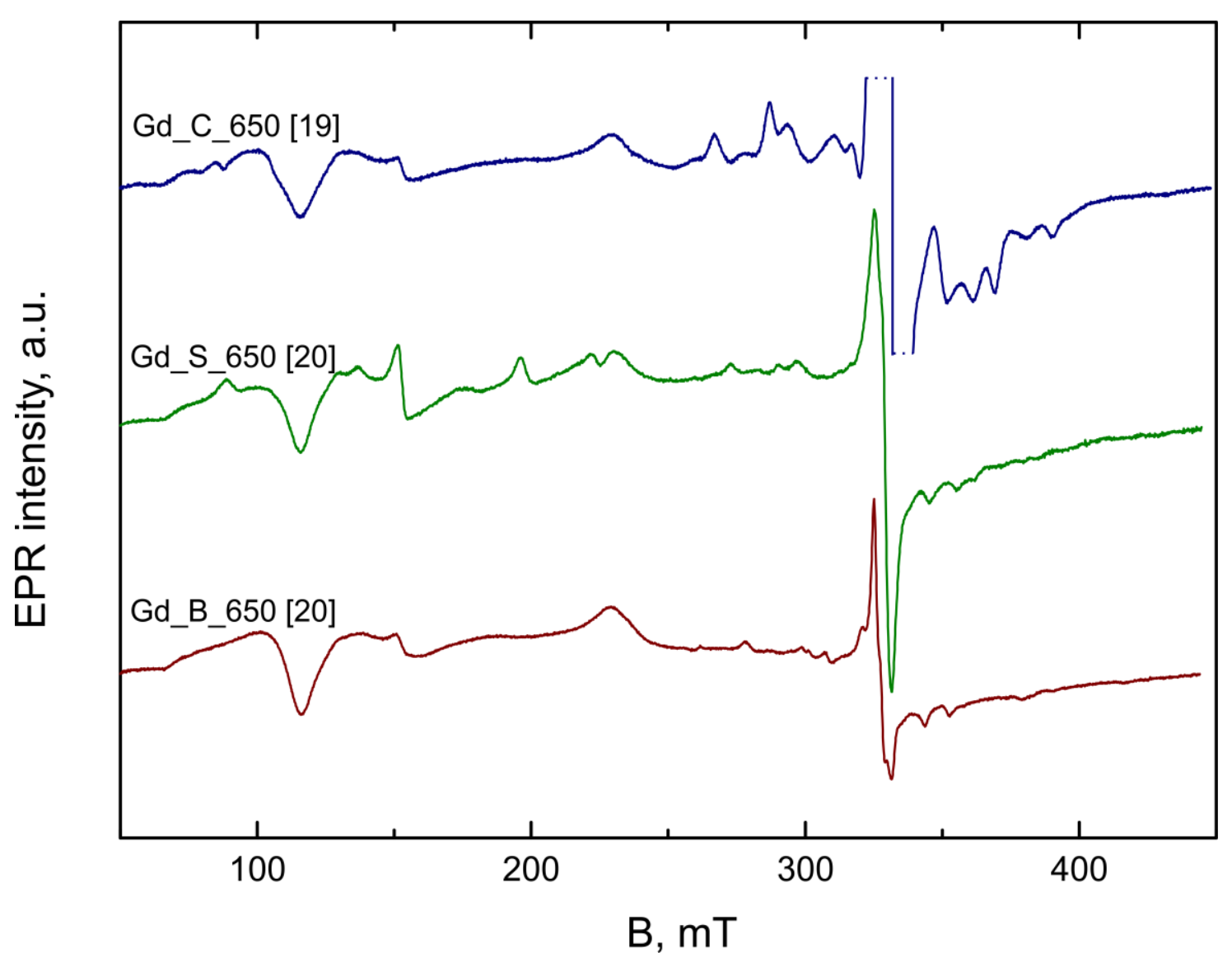

Fig. 6. EPR spectra of glass ceramics containg $\mathrm{CaF}_{2}$ [19], $\mathrm{SrF}_{2}$ and $\mathrm{BaF}_{2}$ [20] nanocrystals.

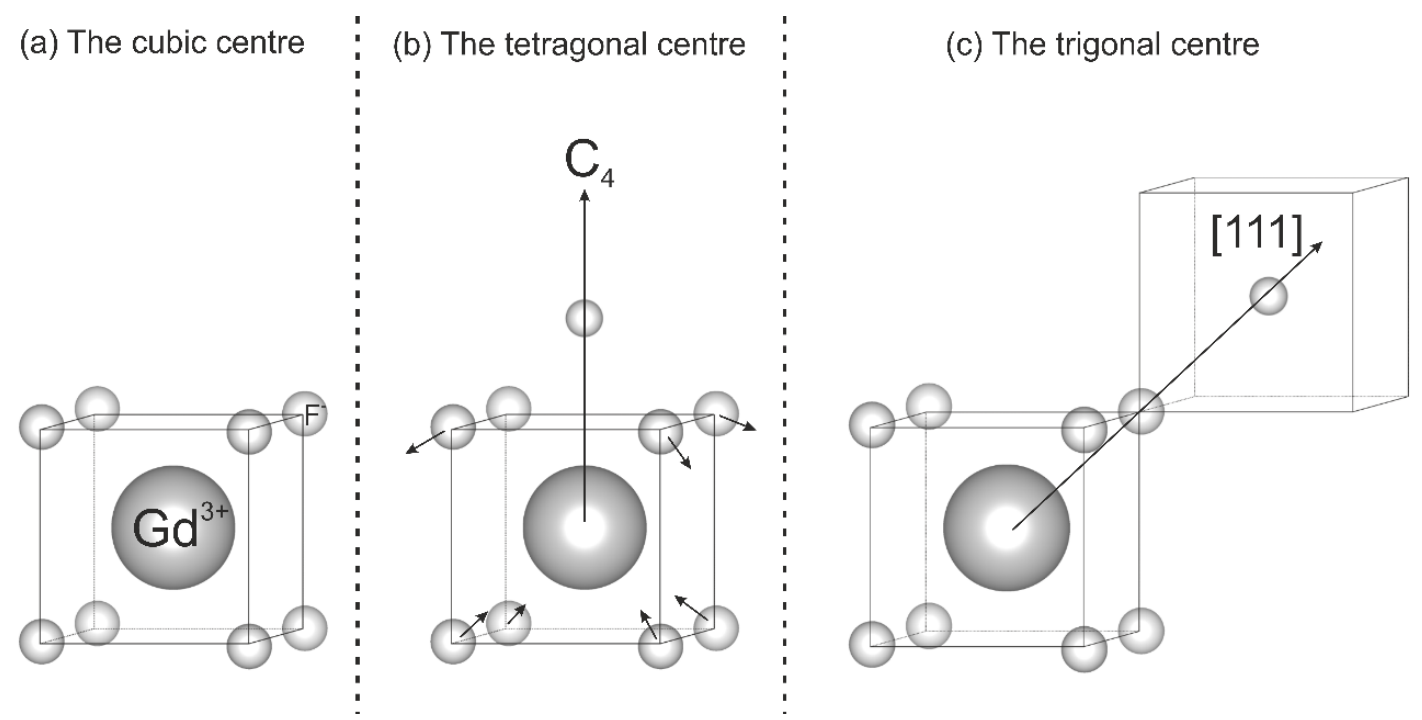

Fig. 7. Possible $\mathrm{Gd}^{3+}$ centres in fluorite structure single crystals. Adaptations from [33], [34] and [35] respectively. 